\title{
Towards an Effective Framework for Integrating Educational Software into Health Informatics Curricula
}

\author{
Ali H. Alharbi
}

\begin{abstract}
In the last few years, the use of information technology to improve the quality of healthcare services has challenged healthcare organizations to adjust to these new developments. Consequently, there is an increasing demand to prepare health informatics professionals to be a driving force in the adoption and implementation of health information technology projects. This paper presents the results of an exploratory study conducted to gain insight into the potential benefits and challenges related to the integration of an educational health information system into an introductory course on health informatics. The study aims to achieve an effective framework for embedding educational software into undergraduate health informatics courses. The students who participated in this study used the system to gain practical experience with how a health informatics system performs its core functions and to discover the importance of integration between different parts of the system. The results of the study revealed that integrating health informatics software into undergraduate courses has positive impacts on the learning process. However, the study identified various barriers that should be taken into consideration to achieve educationally effective integration of health informatics software into the teaching environment.
\end{abstract}

Index Terms-Health informatics education, virtual training, educational software.

\section{INTRODUCTION}

Adopting information and communication technology in healthcare sectors has placed greater challenges on health organizations and academic institutions to prepare a skilled workforce to address these challenges. There is an increasing demand for professionals who can accelerate and facilitate the transition from traditional paper-based healthcare environments to the large-scale adoption of health information systems [1].

Healthcare-related academic programs have relied on internships at the end of their programs to provide students with hands-on experience.

However, to ensure that healthcare professionals acquire the required information and communication skills, academic institutions should enhance their programs by integrating hands-on experience using different types of information technology software into their curricula [2].

Despite the increasing motivation of healthcare organizations to adopt information technology projects, there are a number of barriers that cause these projects to fail. According to [3], one of the top challenges that hinders the

Manuscript received August 19, 2015; revised November 3, 2015.

Ali H. Alharbi is with the Department of Health Informatics, Qassim University, Bukairiyah, Saudi Arabia (e-mail: ahhrbie@qu.edu.sa). adoption of healthcare information technology software is the time it takes to learn a new computer system, which may distract healthcare professionals and negatively affect their interactions with patients. A lack of IT expertise in healthcare organizations is also among the top barriers to large-scale adoption and implementation of health information systems [4].

To cope with the increased demand for healthcare informatics professionals, academic institutions around the world are currently running a number of educational programs that aim to prepare health informatics professionals who can facilitate the implementation of various health information technology projects. An important part of any academic program is to provide students hands-on experience that can help them understand how concepts work in practice.

Several initiatives have recently been implemented to develop a skilled and competent health informatics workforce. The Australian Health Informatics Education Council (AHIEC)has developed a framework to define the scope of health informatics and to identify health informatics domains, competencies and skills required for health informatics professionals [5]. The AHIEC framework lists and defines competencies to help education providers plan and design their curricula. A number of competencies are directly related to the importance of health informatics professionals possessing deep knowledge of the characteristics and functionalities as well as various examples of health information systems. The Canadian Health Informatics Association $(\mathrm{COACH})$ developed a core set of competencies that are broadly categorized into seven different domains[6]. The competencies focus on the skills, knowledge and attitudes necessary for health informatics professionals to work effectively, regardless of their original career before entering the field of health informatics. The $\mathrm{COACH}$ framework also pays attention to the importance of health informatics professionals acquiring the practical skills required to effectively and efficiently manage patient and clinical data and information.

Electronic health records (EHRs) are an example of systems that have been implemented by a large proportion of healthcare organizations worldwide. An EHR is a "longitudinal electronic record of patient health information generated by one or more encounters in any care delivery setting. Included in this information are patient demographics, progress notes, problems, medications, vital signs, past medical history, immunizations, laboratory data and radiology reports" [7]. The rate of adoption of EHRs by physicians and healthcare organizations has increased dramatically worldwide in the last few years [8]-[12].

Health informatics academic programs should involve 
practical training with EHR software and technology to be more effective. Integrating practical EHR training into introductory health informatics courses can increase student awareness and skills in dealing with EHR software. However, this is not a straightforward task.

This study investigated the educational effectiveness of integrating a health informatics system, i.e., EHR software, into undergraduate health informatics courses. The aim of the investigation was to uncover difficulties and misconceptions related to the use of EHR software in an undergraduate health informatics course. The study utilized mixed methods data collection techniques that comprised a questionnaire and a focus group as well as observations of undergraduate students during sessions using EHR software. The results of the study have a number of implications for the improvement of health informatics education, especially in developing countries. The study aimed to shed light onto the following issues:

1) Student perceptions of the integration of educational health informatics software into the undergraduate curriculum.

2) Characteristics of education software that students consider the most useful.

3) Characteristics of the education software that can cause misunderstanding and difficulties.

\section{RELATED RESEARCH}

\section{A. Health Informatics Education}

Health informatics, a new emerging academic discipline, is an area that has received increasing attention in the last few years due to the adoption of e-health strategies by healthcare organization. Health informatics, as defined by the U.S National Library of Medicine, is "the interdisciplinary study of the design, development, adoption, and application of IT-based innovations in healthcare services delivery, management, and planning" [13]. Students from different backgrounds and with different knowledge bases may choose to join health informatics academic programs. Therefore, teaching and learning health informatics is complex and challenging. Worldwide, academic institutions have been establishing new health informatics academic programs at the undergraduate and graduate levels. Like any other emerging discipline, developing high-quality curricula and learning environments is not an easy task. A great deal must be done to provide support for teachers and students in health informatics programs. Having hands-on experience is one of the essential parts of any health informatics instructional approach to prepare graduates to be a driving force for the successful implementation of e-health strategies. In health informatics academic programs, students should gain practical experience to deal with various health information system components [14].

Potential students in the majority of health informatics programs come from two different backgrounds: information technology (IT) or health science. The academic program must be tailored to both groups to facilitate the interdisciplinary nature of the field of health informatics. If students are IT professionals, they may need more training on healthcare systems and clinical settings. For healthcare professionals, it is essential to broaden their knowledge and experience in dealing with health information systems.

Formal efforts to establish frameworks for health informatics education have started only recently. The recommendations of the International Medical Informatics Association (IMIA) on health informatics education [15] stress the importance of including practical training on health information systems. The Australian Health Informatics Education Council (AHIEC) has established a framework to guide health informatics education in the country and worldwide. The framework focuses on defining the scope, careers and competencies for different areas of health informatics. Similar efforts were also established by the Canadian Health Informatics Association (COACH), which developed a set of competencies categorized into a number of domains to reflect the broad knowledge and skills required for health informatics professionals to work effectively.

In [14], the authors reported their experience with practicums and projects assigned to health and biomedical students between 1990 to 2003 at a number of universities in Germany and Austria. The authors found that the majority of these practicums took place at university medical centers and involved the analysis of health information systems. However, these practicums were time-intensive, and students required comprehensive training on health information management. The study concluded that confronting health and biomedical students with the real-world problems of health information systems is recommended for their success.

\section{B. Using EHRs in Educational Settings}

Few studies have reported the integration of health information systems into undergraduate curriculum. The majority of these studies focus on the use of Electronic Health Record (EHR) software to provide hands-on experience for students.

Hammoud et al. [16]conducted a study to describe the status, opportunities, and challenges of integrating EHR into the teaching of medical students in the United States. The study collected qualitative and quantitative responses using a survey that was distributed to clerkship directors. The study concluded that approximately $64 \%$ of undergraduate medical programs allowed students to have access to EHRs, but only two-thirds allowed students to write notes in the electronic records. Moreover, despite the positive perception of the benefits of integrating EHR training into medical education, the respondents raised a number of concerns. These concerns were related to the way in which students use EHRs and the increased time required by teachers and students to learn how to use the EHR.

Elliott et al. [17]reported their findings evaluating the educational impact of a student-centered EHR system on medical student education. A prototype of the system was designed for a master program in medicine. The participants in the study were first-year medical students at a university teaching hospital. The study utilized a semi-structured interview method with ten participants after they used the system for four weeks. Students identified a number of benefits of using the educational EHRs over the traditional procedure of recording patient data. The results of this study stressed the importance of integrating EHR training from 
earlier clinical encounters and integrating EHR-related learning objectives into the program curriculum. The study noted that further research is required to empirically evaluate the impact of educational EHR systems.

In summary, based on the studies cited in this section, some academic institutions have reported the successful use of EHRs to train their students. However, a number of barriers have been identified. Several factors affect the adoption of EHRs by students and educators. These factors can be broadly categorized into technical and privacy issues. The majority of teaching hospitals do not allow students full access to EHRs to protect patient data, which restricts the student role to that of an observer rather than someone actively involved in using EHRs.

\section{EXPLORATORY STUDY}

This section describes in detail the exploratory study that was conducted to gain insights into issues related to the integration of educational EHR software into an undergraduate health informatics curriculum. The aim of the study was to explore hidden aspects that can contribute to improving the educational effectiveness of having hands-on experience as part of introductory courses on health informatics.

\section{A. The Educational Electronic Health Record Software: Spring Charts}

The study utilized a demo version of Spring Charts [18], an easy-to-use and customizable EHR software program, to allow students to have hands-on experience with the concepts and functions related to any EHR system. The software introduces students to the major functions performed by real EHR systems. Students were also able to install the software as a portable version on their own USB flash memory drives. This method gives students more control over their learning process and allows them to have their own portable lab, which they can use whenever and wherever they choose.

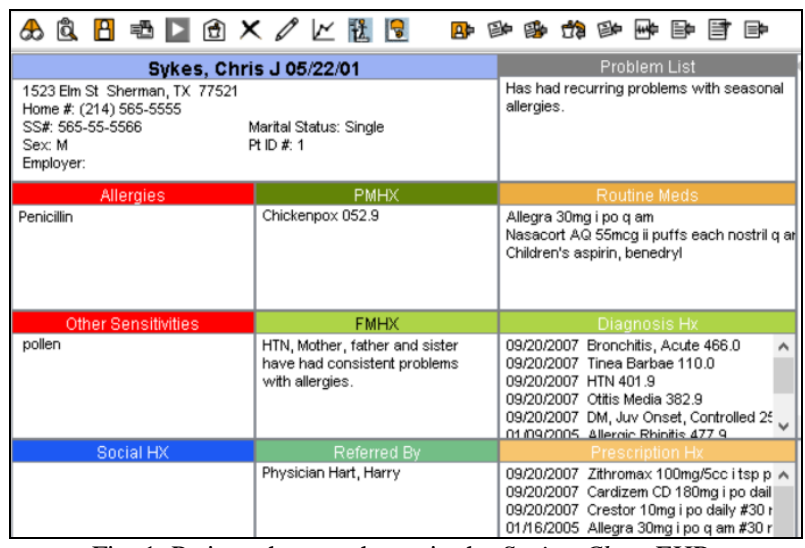

Fig. 1. Patient chart as shown in the Spring Chart EHR.

The system provides various modules, including the following:

The Patient Chart: This module allows students to see how medical doctors can create and manage patient charts during patient visits. Doctors can enter information about the patient and the family medical history, including the medications that have been prescribed for the patient in the past. The chart also records current allergies that the patient may have.

Electronic Prescriptions: This module allows students to gain practical experience with generating electronic prescreens directly within the patient record. As opposed to paper-based prescriptions, the EHR system allows doctors to search and select medicines from an up-to-date database using a standard medical coding system, such as ICD-10 [19], which helps reduce prescription errors.

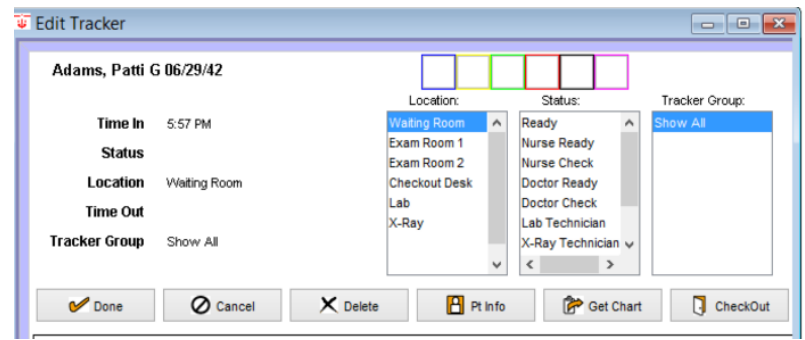

Fig. 2. Patient Tracker helps monitor patient movement inside the health organization.

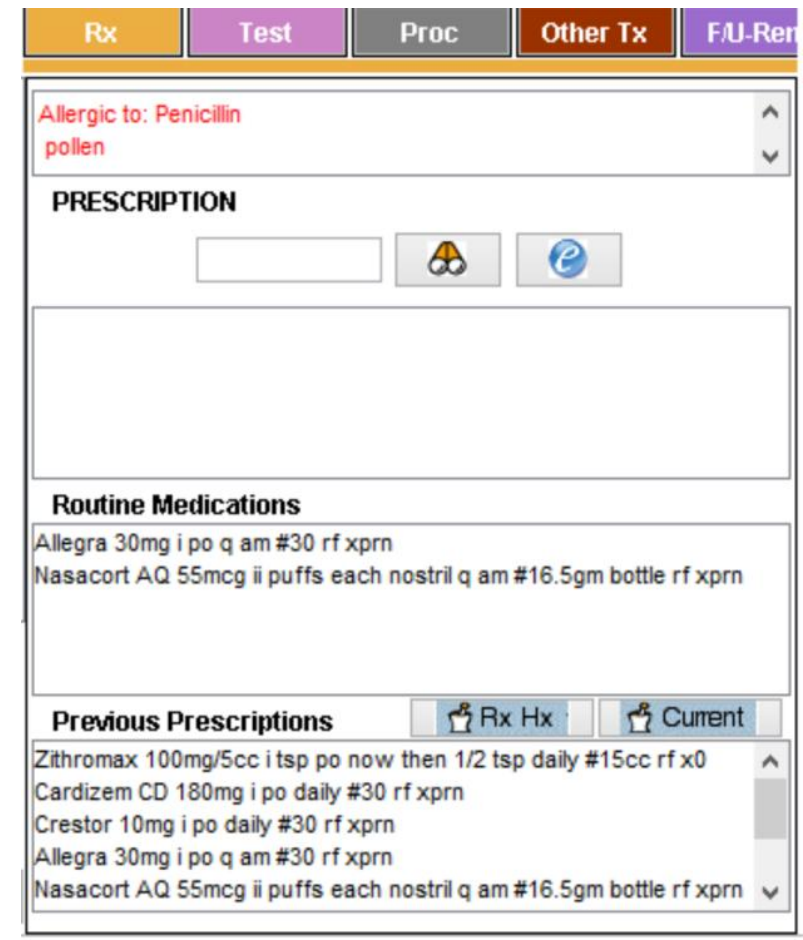

Fig. 3. Generation and management of electronic prescriptions.

\section{B. Design and Methodology}

The main aim of the study reported in this paper was to gain insight into the opportunities and challenges associated with using educational EHR software to teach undergraduate introductory health informatics courses. Therefore, the study is exploratory in nature with regard to uncovering hidden issues that might contribute to the improvement of health informatics education.

\section{Course and Participants}

The study involved undergraduate students who enrolled in an introductory course about Electronic Health Records (EHRs) at the University of Qassim, Saudi Arabia. The total sample size was 63 students. This course covers the study of new trends in the management and processing of health information with an emphasis on EHRs. This course also covers the definition, benefits, standards, functionality, 
confidentiality and security, and impact of EHRs in the healthcare environment. The course explores implementation of EHRs, including the infrastructure required, project management techniques, information technology systems, workflow processes and redesign in various healthcare settings. Topics include an in-depth study of the electronic health record. The course aims to help students achieve the following:

1) Understand what an electronic health record is and how it is used in different healthcare settings.

2) Understand challenges to EHR adoption.

3) Be familiar with the key components needed for the design and implementation of EHR.

4) Assist in identifying functional specification for an EHR system.

5) Identify and describe key privacy and security issues related to EHRs.

6) Have hands-on experiences using EHR software.

\begin{tabular}{|r|l|l|}
\hline $\begin{array}{r}\text { Module } \\
\#\end{array}$ & & Teeks \\
\hline 1 & $\begin{array}{l}\text { Introduction to Electronic Health } \\
\text { Records }\end{array}$ & $1,2,3$ \\
\hline 2 & Standards and Features of EHR & $4,5,6$ \\
\hline 3 & $\begin{array}{l}\text { EHR Regulations, Privacy, and } \\
\text { Security }\end{array}$ & 7,8 \\
\hline 4 & $\begin{array}{l}\text { SpringCharts EHR Software } \\
\text { Introduction and Setup }\end{array}$ & 9,10 \\
\hline 5 & The Clinic Administration and Tools & 11 \\
\hline 6 & The Patient Chart & $12 *$ \\
\hline 7 & The Office Visit & 13 \\
\hline 8 & Tests, Procedures, and Codes \\
\hline & & $*, 15$ \\
\hline$*$ Observations of students were conducted. \\
\hline
\end{tabular}

\section{Data Collection Techniques}

The study employed a mixed methods approach that consisted of both quantitative and qualitative data collection techniques. Qualitative methods of data collection focus on the investigation of the phenomena under study from the point of view of the study participants, while quantitative methods are used to measure students' attitudes and levels of satisfaction toward a particular issue. The following data collection techniques were used:

\section{1) Technology acceptance model (TAM)}

At the end of the study, students were administered a questionnaire, adapted from the Technology Acceptance Model (TAM), to measure their satisfaction with the EHR software with respect to its ease of use and usefulness. TAM, which was originally developed by Davis [20], is an instrument used to predict user acceptance of a technology on the basis of its perceived ease of use and usefulness. TAM has been described as a cost-effective and easy-to-use questionnaire for predicting user acceptance of different systems [21].

\section{2) Focus group}

The focus group is a data collection technique that relies on interviews with a small group of participants in a collaborative and interactive session rather than individually. A focus group can be defined as "a small gathering of individuals who have a common interest or characteristic, assembled by a moderator, who uses the group and its interactions as a way to gain information about a particular issue" [22].

\section{3) Observations}

Observations of undergraduate students interacting with EHR software were employed to determine how students apply concepts covered in lectures. The observations were conducted by giving students certain tasks related to the topic under study. The lecturer watched how students performed each task to identify any difficulties and misconceptions in using the software.

\section{E. Procedure}

First, a systematic literature review was conducted to investigate the extent to which educational software has been integrated into undergraduate health informatics education. Next, a simple and easy-to-use EHR software program was selected and integrated into the lab sessions of an introductory course on Electronic Health Records. Students had to use the software during the lab sessions after covering the theoretical concepts in the lectures to gain hands-on experience. As described in Table I, the first four topics introduced in the course mainly comprised theoretical EHR background, including the definitions and terms used to refer to the functions and features of any EHR system. Lab sessions started after covering all essential theoretical learning content in the lectures, which included EHR definitions, benefits, and standards.

In the first lab session, the lecturer gave students an introduction to the EHR software that was used during the lab sessions. In addition, students were given full instructions and were guided through the process of installing the software as a portable application on their own USB drives. At the beginning of each lab session, the lecturer described how to use the software to perform the tasks covered in the lecture. The lecturer also stressed the importance of new terms introduced during lectures. Next, the lecturer conducted a demo using the software to demonstrate how certain tasks and functions could be performed using the software. Then, students were allowed to use the software to perform certain tasks based on what they learned during the lecture.

As indicated in Table I, students were observed during a number of lab sessions to collect data that could help answer the study questions. During the module that covered Patient Charts, students learned how to enter static and dynamic information related to a patient. They learned how routine medications, diagnoses, and prescriptions can be stored inside a patient chart, as well as the way that information is grouped and organized. Students also encountered the concept of Templates and how they help to increase the efficiency of data entry into the system and reduce errors. During the Office Visit lab, students learned how healthcare practitioners perform tasks related to documenting patient complaints, entering vital signs, and generating notes and electronic prescriptions using an electronic health record system. This helped students gain more knowledge of how these functions are implemented and drew their attention to potential issues that may arise because of flaws in implementing and using these functions.

At the end of the course, students were administered the 
modified TAM questionnaire as described in section D.1. Finally, a focus group was conducted with 15 students to gain an in-depth understanding of their perceptions and difficulties related to using the EHR software as an educational tool. The focus group followed the protocol described in section D.2.

\section{RESULTS AND DISCUSSION}

Table II and Table III present the results of the student responses to the questionnaire items related to the ease of use and usefulness of integrating EHR software into an undergraduate health informatics course. Table II demonstrates that the mean of the student responses on the ease-of-use scale was 6.33 (out of 7), indicating that students strongly agreed that the EHR software was easy for them to use. For the usefulness scale in Table III, the mean of the student responses was 5.93, indicating that students agreed that the EHR software was useful for them to gain hands-on experience with different EHR concepts. Overall, the results of the student perception questionnaire revealed that students found the EHR software to be easy to use and useful.

TABLE II: STUDENT RESPONSES ON THE EASE OF USE OF THE EHR SOFTWARE

\begin{tabular}{|l|r|r|}
\hline Questions & Mean & SD \\
\hline Learning to use the EHR software is easy for me. & 6.33 & 1.15 \\
\hline $\begin{array}{l}\text { I find it easy to make the EHR software do what I } \\
\text { want it to do. }\end{array}$ & 5.67 & 1.53 \\
\hline $\begin{array}{l}\text { I find the EHR software easy to use to learn the } \\
\text { concepts related to the management of patient data. }\end{array}$ & 6.33 & 0.58 \\
\hline I find the EHR software flexible to interact with. & 6.67 & 0.58 \\
\hline $\begin{array}{l}\text { It is easy for me to become skillful at using the EHR } \\
\text { software to manage patient data. }\end{array}$ & 6.67 & 0.58 \\
\hline Overall, I find the EHR software easy to use. & 6.00 & 1.00 \\
\hline Overall (Ease of Use) & $\mathbf{6 . 3 3}$ & $\mathbf{0 . 9 0}$ \\
\hline
\end{tabular}

TABLE III: STUDENT RESPONSES ON THE USEFULNESS OF THE EHR SOFTWARE

\begin{tabular}{|l|l|l|}
\hline Questions & Mean & SD \\
\hline $\begin{array}{l}\text { Using the EHR software enables me to accomplish tasks } \\
\text { more quickly. }\end{array}$ & 5.33 & 2.89 \\
\hline Using the EHR software would improve my learning. & 6.33 & 1.15 \\
\hline $\begin{array}{l}\text { Using the EHR software makes it easier to perform } \\
\text { different tasks related to the management of patient data. }\end{array}$ & 5.76 & 2.31 \\
\hline $\begin{array}{l}\text { Using the EHR software would improve my } \\
\text { productivity. }\end{array}$ & 6.00 & 1.73 \\
\hline Overall, I find the EHR software useful in my learning. & 6.33 & 1.15 \\
\hline Overall (Usefulness) & $\mathbf{5 . 9 3}$ & $\mathbf{1 . 8 5}$ \\
\hline
\end{tabular}

Analysis of the focus group and observational data revealed a number of positive and negative aspects related to the use of educational EHR software.

The students participating in this study considered the integration of EHR education software to be important and useful in providing them with practical experience in storing, retrieving, and processing patient data. Almost all participants agreed that the software gave them hands-on experience using an EHR system, which they had not experienced previously. Using the software immediately after learning the theoretical background was considered by students to be an effective teaching and learning strategy.
Despite the positive experiences reported by students, the data obtained from the student observations and the focus group revealed a number of obstacles, and difficulties related to the ways in which students use different features of the software. It was sometimes difficult to find specific options inside menus, and students had to search inside each menu separately to find specific commands. The large number of options and commands made it difficult for students to easily find what they wanted. This study recommends the use of a customized version of the software for academic purposes in which teachers can control the options and icons that appear to students.

Another significant problem was the language barrier; as the software is completely in English, some students had difficulties understanding certain user interface elements and labels inside the patient chart. In addition, some abbreviations used inside data entry forms were difficult for students to understand because the software was designed based on the American healthcare system. Based on these results, this study recommends that for EHR software to be successfully integrated into undergraduate curricula, this software must be contextualized to support the healthcare system with which students are familiar.

Students were not familiar with the concepts of clients, servers and databases; they did not understand how data are transmitted from the terminals to a central server, and they did not know a great deal with respect to database concepts. Some students thought that the data they entered into the software would be saved locally and only people using the software in the same office would be able to retrieve the information.

\section{IMPLICATIONS FOR HEALTH INFORMATICS EDUCATION}

The results of this study have a number of implications for the improvement of health informatics education.

First, the integration of aspects of health informatics training into the curriculum should be planned early and integrated into the program learning objectives.

It is also important that health informatics software be customized for educational purposes and be flexible and adaptive to student preferences and levels of competencies. The software should also allow teachers and curriculum designers to control the features, modules and user interface based on the requirements and objectives of their courses. Additionally, it is essential that the software is contextualized and designed based on the healthcare system with which students are familiar.

Finally, to increase the educational effectiveness of integrating health informatics software into the educational process, the software can be linked seamlessly to a supporting learning management system. This integration provides the ability for teachers and students to control the learning process. A learning management system can also support certain intelligent features, such as learning analytics and recommender systems [23]. Learning analytics provide data about student behavior inside the system. These data can be analyzed to understand how students are using the software. The recommender systems can use the results of the analysis to recommend learning material that can help students acquire 
essential knowledge to better understand the concepts implemented in the software.

\section{CONCLUSION}

Integrating health informatics software into undergraduate curriculum can give students hand-on experience with the management of patient health-related data. However, there is limited research on the student experience and challenges related to the use of EHR software as a learning tool in academic settings. This paper investigated the effectiveness of integrating an EHR software program into an undergraduate health informatics course. The study revealed that students were highly satisfied with the educational effectiveness of using the software as a teaching and learning method, and they found it to be useful and easy to use. However, the study revealed various difficulties arising during student use of the software. These difficulties included ambiguous terminology, language barriers, and a lack of understanding regarding certain information and communication concepts. Recommendations from this study can be useful in enhancing undergraduate health informatics curricula by stressing the fact that health informatics software should be customized and contextualized to be compatible with student backgrounds and experience and be adaptive to meet the course requirements.

\section{ACKNOWLEDGEMENT}

The author gratefully acknowledges Qassim University, represented by the Deanship of Scientific Research, on the material support for this research under the number (3413) during the academic year 1436 AH / 2015 AD"

\section{REFERENCES}

[1] W. Hersh, A. Margolis, F. Quirós, and P. Otero, "Building a health informatics workforce in developing countries," Health Affairs, vol. 29, pp. 274-277, 2010

[2] E. Costello, M. A. Corcoran, J. S. Barnett, M. C. Birkmeier, R. Cohn, O. Ekmekci et al., "Information and communication technology to facilitate learning for students in the health professions: Current uses, gaps, and future directions," Online Learning: Official Journal of the Online Learning Consortium, vol. 18, 2014.

[3] H. A. DePhillips, "Initiatives and barriers to adopting health information technology," Disease Management \& Health Outcomes, vol. 15, pp. 1-6, 2007.

[4] S. Ajami and R. Arab-Chadegani, "Barriers to implement electronic health records (EHRs)," Materia socio-medica, vol. 25, p. 213, 2013.

[5] AHIEC. (May 18, 2011). Health Informatics Scope, Careers and Competencies. [Online]. Available: http://www.ahiec.org.au/docs/AHIEC_HI_Scope_Careers_and_Comp etencies_V1-9.pdf

[6] $\mathrm{COACH}$, Health Informatics Professional Core Competencies Version 3.0, 2011.

[7] HIMSS. (March 22, 2014). Electronic Health Records. [Online]. Available: http://www.himss.org/library/ehr/

[8] I. M. Xierali, R. L. Phillips, L. A. Green, A. W. Bazemore, and J. C. Puffer, "Factors influencing family physician adoption of electronic health records (EHRs)," The Journal of the American Board of Family Medicine, vol. 26, pp. 388-393, 2013.
[9] A. Parsons and W. Wu, "In response to: Electronic health records in small physician practices: availability, use, and perceived benefits," Journal of the American Medical Informatics Association: JAMIA, vol. 18 , p. 726, 2011

[10] D. Charles, J. King, V. Patel, and M. F. Furukawa, Adoption of Electronic Health Record Systems among US Non-federal Acute Care Hospitals: 2008-2012, Office of the National Coordinator for Health Information Technology, 2013.

[11] S. Duennebeil, A. Sunyaev, J. M. Leimeister, and H. Krcmar, "Strategies for development and adoption of EHR in German ambulatory care," in Proc. 2010 4th International Conference on NO PERMISSIONS, Pervasive Computing Technologies for Healthcare (Pervasive Health), 2010, pp. 1-8.

[12] A. K. Jha, D. Doolan, D. Grandt, T. Scott, and D. W. Bates, "The use of health information technology in seven nations," International Journal of Medical Informatics, vol. 77, pp. 848-854, 2008.

[13] K. Ong. (April 11, 2014). Health Informatics Defined. Available: http://www.himss.org/ResourceLibrary/genResourceDetailPDF.aspx? ItemNumber $=27767$

[14] R. Haux, E. Ammenwerth, A. Häber, G. Hübner-Bloder, P Knaup-Gregori, G. Lechleitner, et al., "Medical Informatics Education Needs Information System Practicums in Health Care Settings-Experiences and Lessons Learned from 32 Practicums at Four Universities in Two Countries," Methods Inf Med, vol. 45, pp. 294-299, 2006.

[15] J. Mantas, E. Ammenwerth, G. Demiris, A. Hasman, R. Haux, W. Hersh, et al., "Recommendations of the International Medical Informatics Association (IMIA) on education in biomedical and health informatics-1st revision," Methods of information in medicine, vol. 49, pp. 105-120, 2010.

[16] M. M. Hammoud, K. Margo, J. G. Christner, J. Fisher, S. H. Fischer, and L. N. Pangaro, "Opportunities and Challenges in Integrating Electronic Health Records Into Undergraduate Medical Education: A National Survey of Clerkship Directors," Teaching and Learning in Medicine, vol. 24, pp. 219-224, 2012/07/01 2012.

[17] K. Elliott, T. Judd, and G. Mccoll, "A student-centred electronic health record system for clinical education," Studies in health technology and informatics, vol. 168, pp. 57-64, 2010.

[18] B. Hamilton. (2009, 20 April). Electronic Health Records. [Online]. Available:

http://highered.mheducation.com/sites/0073374008/student_view0/sp ringcharts.html

[19] W. H. O. WHO. (May 22, 2011). International Classification of Diseases $\quad(I C D) . \quad$ [Online]. Available: http://www.who.int/classifications/icd/en/

[20] F. D. Davis, "A technology acceptance model for empirically testing new end-user information systems: Theory and results," Massachusetts Institute of Technology, 1986.

[21] M. G. Morris and A. Dillon, "The influence of user perceptions on software utilization: Application and evaluation of a theoretical model of technology acceptance," IEEE Software, vol. 14, pp. 58-6, 1997.

[22] A. Williams and L. Katz, "The use of focus group methodology in education: Some theoretical and practical considerations," IEJLL: International Electronic Journal for Leadership in Learning, vol. 5, 2001.

[23] E. Duval, "Attention please! Learning analytics for visualization and recommendation," in Proc. the 1st International Conference on Learning Analytics and Knowledge, 2011, pp. 9-17.

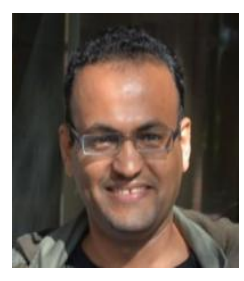

Ali Alharbi is an assistant professor of computer science at Qassim University. He received his $\mathrm{PhD}$ degree in computer science from the University of Newcastle, Australia. Dr. Alharbi is currently the head of the Department of Health Informatics at Qassim University. His research interests include health informatics, e-learning, educational technology, learning analytics, informatics and computer science education. He is interested in improving self-regulated learning by designing adaptive and personalized e-learning systems. 